\title{
A PAISAGEM NA ÁREA DE INFLUÊNCIA DA USINA HIDRELÉTRICA DO FUNIL (UHE-FUNIL), PERCEBIDA ATRAVÉS DO EIA-RIMA
}

\author{
THE LANDSCAPE IN THE INFLUENCE AREA OF THE FUNIL HYDROELECTRIC POWER \\ STATION REALIZED THROUGH ITS EIA-RIMA
}

\author{
Silvério José Coelho \\ Engenheiro agrônomo e doutorando em Manejo Ambiental \\ e-mail:sjcoelho65@gmail.com
}

José Aldo Alves Pereira

Engenheiro florestal e doutor pela UFMG

e-mail: j.aldo@ufla.br

\section{RESUMO}

A construção de uma hidrelétrica provoca grandes transformações na paisagem regional, provocando rápida degradação ambiental, contrária ao processo milenar de sua formação. A implantação de hidrelétricas é definida por pré-requisitos, como a disponibilidade de água, topografia e geologia adequadas e, assim, o estudo integral da paisagem - sistema em constante transformação, não faz parte do processo. A Usina Hidrelétrica do Funil, UHEFunil, foi construída no alto do rio Grande, próximo à cidade de Lavras - MG. Os primeiros estudos são da década de 1960; os estudos e relatórios de impacto ambiental - EIA-RIMA de 1991/1992 e, em 2003, iniciou-se a operação comercial. Objetivou-se, nesta pesquisa, analisar toda a documentação referente ao EIA-RIMA, para perceber como a paisagem na área de influência da usina foi considerada antes, durante e após sua construção; objetivouse também verificar se os estudos apontaram alternativas para o aproveitamento ou a preservação dos recursos naturais, questionando-se sobre a relação entre os benefícios da geração de energia elétrica e os conseqüentes danos ambientais. Os resultados conduziram a uma análise temporal com três estágios de transformação da paisagem: dos primórdios da ocupação antrópica até a época do EIA-RIMA; modificações durante a construção e enchimento da barragem e o surgimento de novas paisagens após a construção da usina.

Palavras-chave: Paisagem, usina hidrelétrica, meio ambiente, EIA-RIMA, impacto ambiental.

\begin{abstract}
The building of a hydroelectric power station provokes great transformations in the regional landscape, provoking a fast environmental degradation in opposition to its millenarian formation process. The implantation is defined by pre-requirements such as water availability, appropriate topography and geological factors and in this way, the integral study of the landscape, a system in constant transformation, doesn't take part in the process. The Funil Hydroelectric Power - UHE-Funil was built in the upper part of the Rio Grande, close to the town of Lavras - MG. The early studies were done in the 1960's; the environmental impact studies and reports - EIA-RIMA are from 1991/1992 and in 2003, the commercial operation was started. It was intended in this research work to analyze the whole of documentation regarding to the EIARIMA of the hydroelectric power, to realize how the landscape in the influence area of the hydroelectric had been considered before, during and after the building of the barrage. Another purpose was to identify whether the studies had pointed out alternatives to the use or preservation of natural resources, which
\end{abstract}


would permit to question about the relationship between the benefits produced by hydroelectric energy generation and the consequent environmental damages. The results led to a temporary analysis with three landscape transformation stages: since the origin of man's occupation till the time of the EIA-RIMA elaboration; modifications during the building and filling of the barrage and the appearance of new landscapes after its building.

Key words: Landscape, hydroelectric power, environment, EIA-RIMA, environmental impact.

\section{INTRODUÇÃO}

A construção de uma usina hidrelétrica provoca grandes transformações na paisagem da região onde se instala o empreendimento, em um processo rápido de degradação ambiental, em oposição ao lento movimento milenar de formação da paisagem durante as sucessivas eras geológicas.

A viabilidade desse tipo de empreendimento é definida por pré-requisitos, como a disponibilidade de água e a existência de condições topográficas e geológicas adequadas à construção de uma usina, sem haver, contudo, um estudo integral dos ecossistemas da região que aponte, inclusive, alternativa para o aproveitamento ou a preservação de seus recursos naturais e socioeconômicos.

No Brasil, $75 \%$ da matriz energética brasileira é composta de energia elétrica proveniente de hidrelétricas. No entanto, a avaliação do significado socioambiental da construção de uma hidrelétrica envolve a difícil ponderação de usufruir dos benefícios proporcionados pela geração de energia elétrica e arcar com os impactos negativos decorrentes da implantação do empreendimento (Ministério do Meio Ambiente, 2000).

A transformação do complexo ecossistema de um ambiente lótico (rio) em lêntico (lago), de maneira brusca, desencadeia uma série de desequilíbrios ecológicos e sociais. Do ponto de vista ambiental, os impactos negativos vão desde a perda da vegetação nativa, com diminuição da biodiversidade, até a perda de paisagens culturais e, mesmo, as naturais, formadas pelo rio com suas corredeiras, cachoeiras, praias, além do aumento dos processos erosivos e de polventes.

A obrigatoriedade de estudo prévio de impacto ambiental para instalação de obra ou atividade potencialmente causadora de significativa degradação do meio ambiente está na Constituição Federal, Título VIII - Da Ordem Social, Capítulo VI - Do Meio Ambiente, Art. $225 \S 1$, inciso IV (1999).

A Resolução Conama n. 001/86 estabelece que o estudo prévio dos impactos ambientais - EIA - é o instrumento de controle e planejamento ambiental, obrigatório em qualquer decisão pública ou privada que possa causar dano ao meio ambiente. Complementarmente, o Relatório de impactos ambientais - Rima - deve ser o reflexo das conclusões obtidas no EIA, contendo recomendações técnicas em linguagem acessível ao público, devendo, ainda, ser ilustrado por tabelas, mapas, quadros, gráficos ou outras técnicas de comunicação visual (PEREIRA, 2001).

A extensão geográfica dos impactos ambientais provocados pela construção de uma hidrelétrica está contida na Área de Influência - Al do empreendimento e, segundo Muller (1995), em termos socioambientais, inclui toda a região afetada pelo empreendimento, 
podendo ser direta quando inclui áreas destinadas à infra-estrutura, ao sítio da obra e ao polígono do reservatório. Pode, também, ser indireta ou regional, correspondendo, em geral, à bacia de drenagem a montante do reservatório e os municípios que foram atingidos parcialmente. Quanto à área diretamente afetada - ADA, ela diz respeito à área inundada e o entorno do reservatório.

No caso da construção de hidrelétricas, as Centrais Elétricas Brasileiras - Eletrobrás (1986), recomendam as seguintes etapas de planejamento: estimativa preliminar, inventário, viabilidade, projeto básico e projeto executivo.

Os primeiros estudos sobre o aproveitamento integral do rio Grande remontam à década de 1950 do século passado, sendo constituídos por um inventário do referido rio com a fixação de sua divisão de queda. Já os estudos para Aproveitamento Hidrelétrico do Funil - AHE-Funil são da década de 1960, tendo sido atualizados no início da década de 1990. São também dessa época (1991/1992) os Estudos e Relatórios de Impacto Ambiental - EIA-Rima, realizados na fase de estudo de viabilidade do projeto (AHE-Funil, 2005)

A apresentação do EIA-Rima ao órgão licenciador ambiental permite requerer três licenças: prévia (LP), para dar início à etapa de projeto básico; de instalação (LI), como pré-requisito do início das obras; e de operação (LO), permitindo o enchimento do reservatório e a operação comercial (FEAM, 2005).

O Consórcio AHE-Funil foi constituído em 1997, sendo a LI concedida pelo Conselho Estadual de Política Ambiental - Copam, no ano de 2000. Em 2002, foi concedida a LO para a Usina Hidrelétrica do Funil - UHE-Funil e, em janeiro de 2003, ocorreu a entrada em operação comercial da primeira unidade geradora, com potência instalada de 60 MW (AHE-Funil, 2005).

A fase de operação de uma usina hidrelétrica é aquela na qual o reservatório já está formado, estabelecendo uma nova paisagem local, e as pessoas residentes no entorno têm de adaptar-se a essa nova paisagem, que passa a ser parte integrante de suas vidas.

Ainda que a Licença Prévia (LP) para a instalação de uma hidrelétrica seja precedida de estudos de impacto ambiental e seus correlatos, que se estendem até a fase de operação da usina, a legislação ambiental específica para esses casos é, algumas vezes, falha e ambígua, além de ficar sempre sujeita a interesses econômicos e políticos que quase nunca privilegiam o meio ambiente. Muitas das medidas mitigadoras e condicionantes propostas pelo EIA-RIMA e documentos correlatos, como o Plano de Controle Ambiental - PCA, não são implementados ou sofrem modificações devido a interesses diversos.

Fearnside (1990), ao referir-se ao desastre ambiental decorrente da construção da Hidrelétrica de Balbina, no estado do Amazonas, com estudos de viabilidade técnica e econômica da década de 1970, mas cuja construção só se efetivou em 1987, afirma que intervenções não-precedidas pelo devido planejamento e que desconsideram os princípios ecológicos básicos da região têm provocado, com freqüência, grandes alterações de características naturais, muitas delas de caráter irreversível. 
Rosa et al (1995) tomam como base a construção da Hidrelétrica de Balbina para exemplificar como se dá a interação entre estado - energia elétrica e meio ambiente no Brasil. Concluíram que o sistema atual de avaliação de impactos ambientais tem uma influência indesejável sobre a política científica, não enfrentando causas subjacentes aos processos de desenvolvimento pernicioso ao meio ambiente, sendo, inclusive, incapaz de sustar projetos irreversíveis.

Nos Estados Unidos, segundo Alier (1999), os bens ambientais mais discutidos são aqueles com um valor recreativo e, sob essa ótica, o meio ambiente não é visto como um fornecedor de recursos e serviços naturais insubstituíveis como condição para a produção e para a vida em si mesma, mas como uma fonte de valores recreativos. Exemplifica esse processo por meio do "critério de Krutilla", utilizado nos anos 60 para a valorização das belas paisagens de Hells Canyon, ameaçadas por projetos hidrelétricos. Krutilla modificou a análise custo/benefício, dando maior peso ao valor recreativo da natureza, alegando que a produção de eletricidade estaria cada vez mais barata, ao passo que o valor recreativo de uma beleza natural (como o Heels Canyon) aumentaria com o tempo.

Os conflitos existentes entre preservação ambiental e desenvolvimento econômico, no entanto, estão longe de alcançar o patamar desejável para um desenvolvimento sustentável tanto nos Estados Unidos quanto no Brasil.

Em empreendimentos de grande impacto ambiental, a análise da paisagem, como elemento integrador dos componentes de um ecossistema, pode colaborar, introduzindo indicadores de sustentabilidade na análise metodológica, com ênfase em variáveis ambientais e sociais relacionadas à paisagem. A construção desses indicadores se faz necessária para saber o custo do progresso no presente e para as gerações futuras (REIS et al, 2005).

A análise da paisagem pode contribuir, também, como forma de avaliar a eficácia dos Estudos e Relatórios de Impacto Ambiental - EIA-Rima, além de propor medidas e ações complementares e fiscalizadoras dos planos e projetos propostos, com o objetivo de mitigar os impactos ambientais.

Objetivou-se, com o presente trabalho, analisar toda a documentação que compõe - ElA-Rima e, mediante uma análise temporal, perceber como a paisagem na Área de Influência - Al do Aproveitamento Hidrelétrico do Funil - AHE-Funil, e que culminou com a construção da Usina Hidrelétrica do Funil - UHE-Funil, foi considerada antes, durante e após a construção da barragem.

\section{MATERIAL E MÉTODOS}

Esta pesquisa teve como base os documentos relativos à construção do Aproveitamento Hidrelétrico do Funil - AHE-Funil, consultados na Fundação Estadual do Meio Ambiente - Feam, em Belo Horizonte-MG, no Instituto Brasileiro do Meio Ambiente - Ibama, Regional de Lavras-MG e na prefeitura de ljací-MG, extraindo-se deles as informações que consideravam, direta ou indiretamente, a área de influência do empreendimento como paisagem. 
Os documentos pesquisados foram os quatro volumes do EIA relativos a diagnósticos dos meios físico, biótico e socioeconômico e documentos correlatos relativos a programas, projetos e legislação, além do relatório de Impacto Ambiental - Rima. Também foram consultados os documentos contendo informações complementares relativas à geologia, uso da terra, solos, vegetação, aspectos sociais e econômicos, avaliação de impactos e medidas mitigadoras e seleção de áreas para unidade de conservação.

Características gerais do empreendimento e localização da área de estudo: com uma potência instalada de $180 \mathrm{MW}$, a UHE-Funil foi implantada no rio Grande, entre os municípios de Lavras e Perdões, na região sul do estado de Minas Gerais. Com energia suficiente para abastecer uma cidade de 500 mil habitantes, possui um lago com capacidade para armazenar 258 milhões de $\mathrm{m}^{3}$ de água, em uma extensão de 34,71 km², formando uma lâmina d’água com nível constante.

A UHE-Funil está localizada entre as coordenadas UTM 500 km, 516 km E e 7.650 km, 7.670 km N, fuso 23 k, datum SAD 69, sendo a barragem situada a 950 km da foz, entre os municípios de Lavras e Perdões. $\bigcirc$ posto fluviométrico de referência é composto pelos municípios de Itutinga, Madre de Deus de Minas, Itumirim, Ibituruna e Ribeirão Vermelho, além do distrito de Macaia e da Fazenda Laranjeira. Os principais afluentes do rio Grande com cursos inundados pelo reservatório são os rios das Mortes e Capivari.

Do ponto de vista do meio físico, o Relatório de Impacto Ambiental - Rima - define a Área de Influência - Al e Área Diretamente Afetada - ADA como:

- Área de Influência - Al: Está contida na bacia de drenagem contribuinte ao futuro reservatório, limitada em quatro pontos: no rio Pirapetinga, nas proximidades de Bom Sucesso; no rio das Mortes, pelas serras de Ibituruna e Bom Sucesso; no rio Grande, próximo ao local da futura UHE-São Miguel, e, no rio Capivari, pelas serras do Campestre e da Estância. Inclui uma área a jusante da barragem, até o ribeirão Conta das Lágrimas.

- Área Diretamente Afetada - ADA: área inundada e o entorno do reservatório, diferindo do limite da $\mathrm{Al}$ ao norte, em que acompanha a coordenada $21^{\circ} 05^{\prime}$, percorrendo os divisores de água, e no trecho do rio Capivari que vai das serras do Campestre e da Estância até o povoado de Rosário e serra do Jaci, onde o limite passa pelos divisores

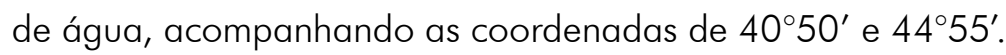

A Resolução Conama n. 001/86 estabelece a obrigatoriedade de elaboração dos Estudos de Impacto Ambiental - EIA e seu respectivo Relatório de Impacto Ambiental - Rima, cabendo a esse último definir os limites da Área de Influência - Al, em função dos limites da área geográfica que será direta ou indiretamente afetada pelos impactos. Também, segundo essa resolução, o ElA deve desenvolver um diagnóstico ambiental da Al do projeto, com a seguintes diretrizes:

- Meio físico: subsolo, águas, ar e clima, destacados os recursos minerais, a topografia, os tipos e aptidões do solo, os corpos dágua, o regime hidrológico, as correntes marinhas e as correntes atmosféricas; 
- meio biológico e ecossistemas naturais: caracterizando a fauna e a flora, destacando as espécies indicadoras da qualidade ambiental, de valor científico e econômico, raras e ameaçadas de extinção e as áreas de preservação permanente;

- meio socioeconômico: caracterizando o uso e ocupação do solo, os usos da água e a socioeconomia, destacando as relações de dependência entre a sociedade local, os recursos ambientais e a potencial utilização futura desses recursos.

\section{RESULTADOS E DISCUSSÃO}

Pela análise da documentação específica, pôde-se desenvolver uma série temporal da paisagem na área de influência - Al, em três níveis:

- A paisagem, nos primórdios de sua formação e a evolução de sua ocupação antrópica, até a época de elaboração do ElA-Rima;

- previsões de modificações na paisagem para a fase de construção e enchimento da barragem da UHE-Funil;

- estruturas e características previstas no EIA-RIMA para as novas paisagens após a construção da barragem e início da operação.

\section{A paisagem nos primórdios de sua formação e a evolução de sua ocupação antrópica até a época de elaboração do EIA-RIMA}

Os estudos e relatórios de impacto ambiental EIA-Rima, ao realizarem um diagnóstico ambiental, desconstruíram a paisagem na área de influência - Al do empreendimento, fragmentando-a em meio socioeconômico, meio físico e meio biótico, aportando importantes informações sobre a paisagem na região.

O diagnóstico do meio socioeconômico incluiv o levantamento do patrimônio cultural, permitindo entender a ocupação da região, desde os primórdios até os ciclos do ouro, o agropastoril, do café e da industrialização. Os estudos diagnosticaram uma região formada por paisagens arqueológicas e históricas devido à ocupação indígena, à passagem dos bandeirantes e à Estrada de Ferro Oeste de Minas, das quais pouco se sabia.

Os vestígios culturais de populações indígenas encontrados constaram de machados de pedra polida, mãos de pilão e cacos de panelas de barro e cachimbos, possivelmente pertencentes aos índios cataguases.

Os estudos concluíram que pouco se sabe sobre a ocupação pré-histórica do rio Grande, permitindo, porém, inferir que a região teve uma significativa ocupação pré-histórica, de grande potencial arqueológico. No entanto, com a alteração decorrente do empreendimento, não haverá possibilidade de futuras gerações de arqueólogos, com técnicas mais avançadas, poderem obter novas informações sobre o modo de vida dos grupos pré-históricos que ocuparam a região.

O Rima considerou, posteriormente, que a perda do patrimônio arqueológico e histórico deveria ser mais bem descrita na fase executiva do projeto, por meio de recursos de documentação audiovisual, o que, de fato, ocorreu. 
Sobre as atividades antrópicas, o Rima concluiu que elas influenciaram sobremaneira as mudanças na paisagem local, a exemplo do garimpo do ouro, que se esgotou rapidamente, mas não acarretou em estagnação da área, devido às atividades agropecuárias desenvolvidas em paralelo à mineração.

A partir do desenvolvimento da lavoura cafeeira, a região viveu um intenso processo de expansão urbana e demográfica com a implantação da Estrada de Ferro Oeste de Minas, construída no século 19, e possibilitou o escoamento do café para o porto de Santos. Nas margens do rio Grande foi possível encontrar, na época dos estudos, elementos remanescentes dessa estrada, chamada pelos moradores de "bitolinha", além da antiga Estação Ferroviária de Pedra Negra (Figura 1).

Concluiu-se, nesses estudos, que os recursos gerados pela cafeicultura permitiram a acumulação de capitais utilizados para a implantação de indústrias na região.

Há de destacar-se que a área onde se localizava a ponte do Funil constituía uma importante referência histórica e cultural relacionada à passagem dos bandeirantes pela região e à própria origem do município de Lavras, além de fazer parte integrante da paisagem de um dos locais de lazer mais freqüentados antes da construção da hidrelétrica (Figura 2).

Quando da elaboração do EIA-Rima, a região apresentava, além da ponte do Funil, um rico acervo histórico-arquitetônico ainda não pesquisado, a exemplo do Santuário do Funil - único local de culto que existiu às margens do rio Grande, da Gruta de Santo Antônio e de sedes de fazendas, além das catas e regos mineiros constituídos de elementos de atividades mineradoras.

O diagnóstico do meio socioeconômico permitiu caracterizar a paisagem na área diretamente afetada - ADA - como eminentemente antrópica, com característica rural

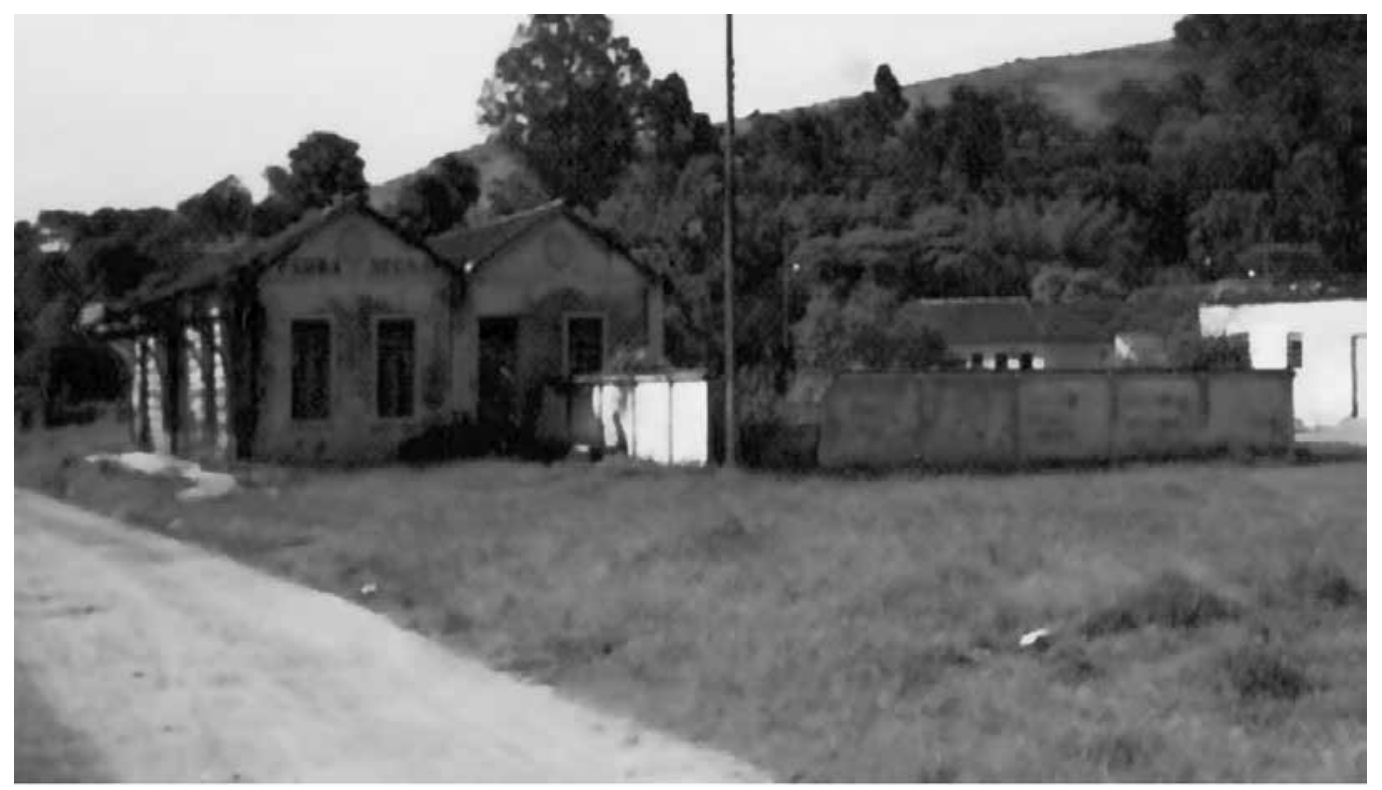

Figura 1: Antiga Estação da Estrada de Ferro Oeste de Minas em Pedra Negra, município de Bom Sucesso, MG

Fonte: Prefeitura de liaci, 2001 


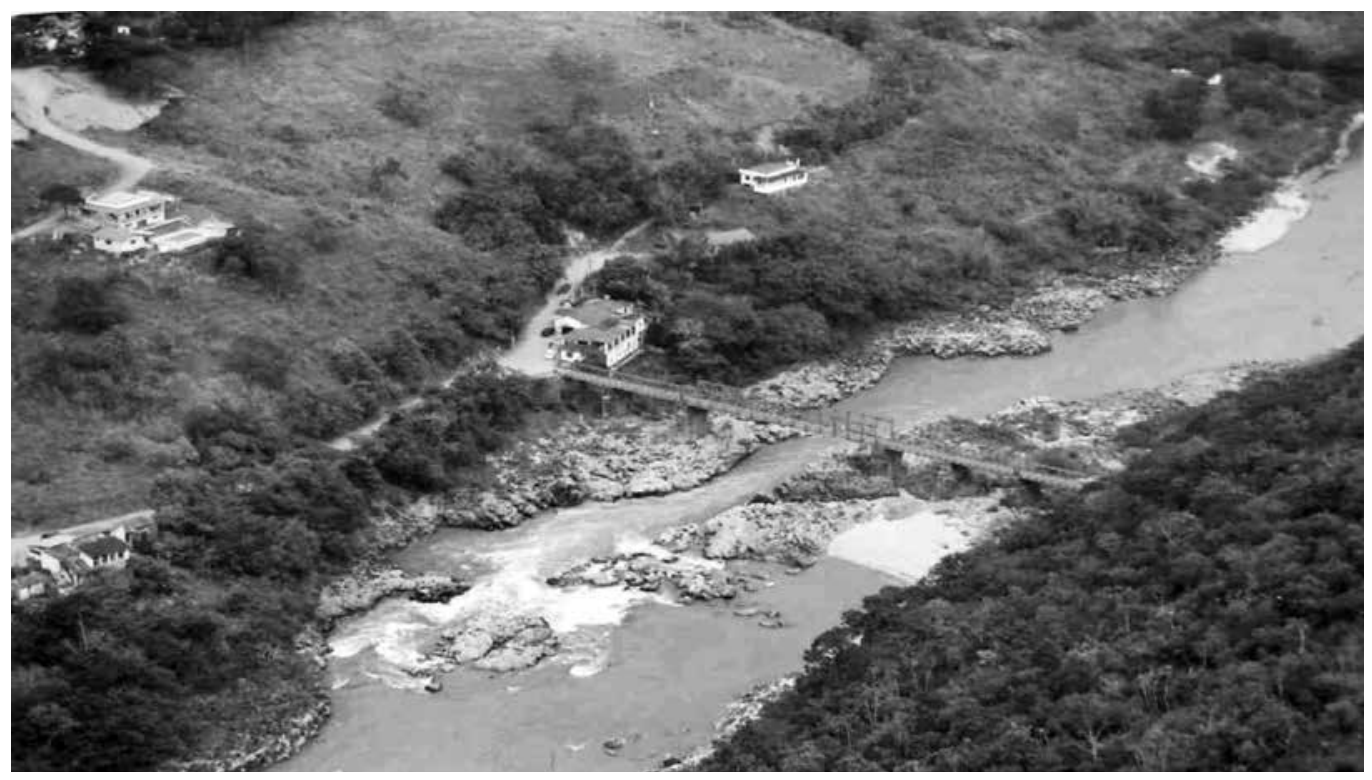

Figura 2: Ponte do Funil, sobre o rio Grande, na divisa entre os municípios de Lavras e Perdões, MG Foto: Wildes, 2001

agrícola e predomínio de pastagens naturais $(53,7 \%)$, seguidas pelas pastagens artificiais $(20,8 \%)$, área plantada (17\%) e matas + capoeiras (5,78\%). Na época, a paisagem rural agrícola caracterizava-se pelo cultivo de café e por culturas temporárias, como milho, feijão e cana, além de pastos e pequenos maciços de florestas plantadas de eucalipto.

Para os estudos de impacto ambiental, o meio físico foi dividido em criptossistema e fenossistema, permitindo, assim, conhecer aspectos geológicos e morfológicos da região.

Do ponto de vista do criptossistema, a área de influência está inserida na unidade geomorfológica "Superfície Cristalina do Alto Rio Grande" ou "Planalto Sul de Minas Gerais". Possui diversidade de tipos litológicos formados na era pré-cambriana, com gênese e evolução variadas, o que, em última análise, reflete em diferentes tipos de solos. $\bigcirc$ fenossistema da área de influência apresenta-se como uma ampla superfície de relevo ondulado, com altitudes mais comuns variando em torno dos 900 metros.

Sobre o fenossistema, o Centro Tecnológico de Minas Gerais - Cetec (1983) dividiu a área de estudos em duas unidades, dentro da classificação geomorfológica: Planaltos Dissecados do Centro-Sul e do Leste de Minas e Depressão do Rio Grande.

Também sob a ótica da geomorfologia, o diagnóstico do patrimônio natural realizado pelo EIA caracterizou a paisagem pelos elementos morfológicos, em três níveis:

a) Elementos morfológicos dos principais rios e seus tributários situados abaixo da cota de inundação e que seriam submergidos: os rios correm, predominantemente, sobre rochas cristalinas (gnaisses, migmatitos, charnockitos e outros), formando meandros, ilhas, corredeiras, cachoeiras e praias.

b) Elementos morfológicos do patrimônio natural característicos de relevos cársticos e localizados na região central da área do empreendimento: configuravam um relevo aplainado, com ocorrência localizada de afloramentos calcários e 
feições cársticas, como paredões, colinas, sumidouros, ressurgências, grułas e abrigos rochosos.

c) Elementos do relevo de destaque regional: picos, serras e maciços rochosos, como a serra do Jaci, com forma retilínea e cortada em um cânion pelo rio Capivari e a Pedra Negra, maciço rochoso com formas arredondadas e encostas convexas.

O diagnóstico do meio biótico, por sua vez, traz importantes informações sobre a estrutura da vegetação na paisagem da área de influência do empreendimento e, segundo Rizzini (1962), está inserida na Província Central e na Subprovíncia do Planalto Central, onde ocorre o cerrado (lato sensu) como formação principal.

Posteriormente, estudos realizados por Gavilanes \& Brandão (1991), no município de Lavras, demonstraram que a cobertura vegetal original encontrava-se extremamente devastada; das formações florestais só restavam capões esparsos na cumieira das elevações, além de estreitas e fragmentadas matas ciliares ao longo dos cursos d'água.

Das formações campestres, o campo cerrado ocupou extensa área no passado, tendo sido reduzido drasticamente pela expansão pecuária, ao passo que os campos de várzea foram substituídos por culturas e/ou pastagens. Os campos limpos e os rupestres, embora submetidos à ação antrópica, ainda mantinham seus limites originais na época do levantamento.

Alguns capões estavam formados por vegetação bem preservada e com significativa riqueza de espécies. Os campos cerrados foram detectados nas zonas de transição entre o cerrado e o campo limpo, principalmente nas serras de Jaci, Ibituruna e Itumirim. O campo rupestre está próximo a ltutinga, bem conservado, e ao longo da rodovia que liga Lavras a S. J. Del Rey. Campos de várzea situavam-se ao longo do rio Grande, na altura da foz dos rios Capivari e das Mortes e no baixo rio Capivari, tendo sido bastante alterados e substituídos por culturas de várzea e pastagens.

Sobre a vegetação nativa na paisagem local, o Rima concluiu que ela foi bastante reduzida ao longo dos anos. O cerrado, o cerradão e os campos de várzea foram as formações vegetais que mais sofreram os impactos da ação do homem e, quando presentes, encontravam-se descaracterizados e restritos a pequenas áreas. $O$ campo cerrado, campo limpo e campo rupestre, ao contrário, apresentaram áreas de distribuição próximas às originais. As pressões antrópicas diagnosticadas na época de realização do EIA-Rima foram as queimadas, o pastoreio e a retirada de madeira para lenha e pequenas construções rurais.

\section{Transformações na paisagem durante as fases de construção e enchimento da barragem do AHE-FUNIL}

Os estudos e relatórios de impacto ambiental - ElA-Rima previram grandes transformações na paisagem da região quando da construção e enchimento da barragem, começando pela remoção da cobertura vegetal nativa para a implantação das obras civis destinadas à criação da infra-estrutura básica, conforme mostra a Figura 3. 
Os estudos de impacto ambiental - ElA descreveram paisagens urbanas, como o distrito de Macaia, parcialmente inundado, e paisagens rurais-urbanas, como o povoado de Pedra Negra e a área do entorno da ponte do Funil que tiveram suas infra-estruturas totalmente inundadas, levantando questões culturais sobre a perda de identidade do lugar e da possível desestruturação de laços afetivos e de amizade.

A Figura 4 mostra a bela região de Pedra Negra, totalmente inundada, e a Figura 5 documenta uma procissão organizada pelos moradores daquela comunidade, como despedida do local, antes de sua desocupação.

O EIA considerou ainda que as alterações da paisagem destruiriam a identificação, em nível simbólico, dos habitantes de Macaia com as características geográficas, arquitetônicas e paisagísticas do local.

Para as fases de construção e enchimento da barragem, o Rima descreveu os impactos no meio biótico, nos aspectos socioeconômicos e nos patrimônios natural, histórico e arqueológico, que sobreviriam com a construção da UHE-Funil. A análise concluiu que a remoção da cobertura vegetal nativa para a construção da UHE-Funil foi considerada como um impacto prejudicial ao meio ambiente e com reflexos negativos porque atuariam diretamente sobre o meio. Os impactos foram considerados de caráter irreversível e permanentes; de curto prazo, porque ocorreram imediatamente após a ação que os causou, e inevitáveis, mesmo com a adoção de medidas mitigadoras ou outros procedimentos.

Há de questionar-se, no entanto, a avaliação da magnitude relativa (grau de comprometimento da qualidade ambiental), considerada baixa para a remoção da cobertura vegetal nativa e alta para a redução na área ocupada pelas formações vegetais, sobretudo a mata, uma vez que a segunda é conseqüência da primeira e ambas foram responsáveis por grandes transformações na paisagem.

Paralelamente à etapa de qualificação dos impactos, foram definidos projetos com o objetivo de mitigá-los. Para a remoção da cobertura vegetal nativa, foi proposto o projeto de criação da reserva ecológica e área de preservação permanente - APP; o primeiro ainda não foi estabelecido e o segundo tem sido reduzido a $30 \mathrm{~m}$ no entorno do lago, em função de projetos turísticos.

No caso do impacto relativo à redução na área ocupada pelas formações vegetais, foi proposto o projeto de resgate da flora na área inundada e o projeto de criação da Área de Preservação - APP, esse último, sem atingir seus objetivos até a presente data. O projeto de resgate da flora poderia ter influenciado a nova paisagem surgida com a formação do lago, fornecendo material para a produção de mudas a serem utilizadas em projetos de recuperação de áreas degradadas, enriquecimento das matas existentes fora da área de inundação e recomposição da cobertura vegetal da ilha. Contudo, esse projeto não teve continuidade, limitando-se apenas à identificação das espécies vegetais existentes na ADA.

A mata foi considerada a formação mais afetada em razão de ocupar, na época, 7,92\% (320 ha) da Área Diretamente Afetada - ADA. A perda da cobertura vegetal implicou em uma modificação drástica da paisagem, inclusive com a supressão e degradação de hábitats para a fauna. 

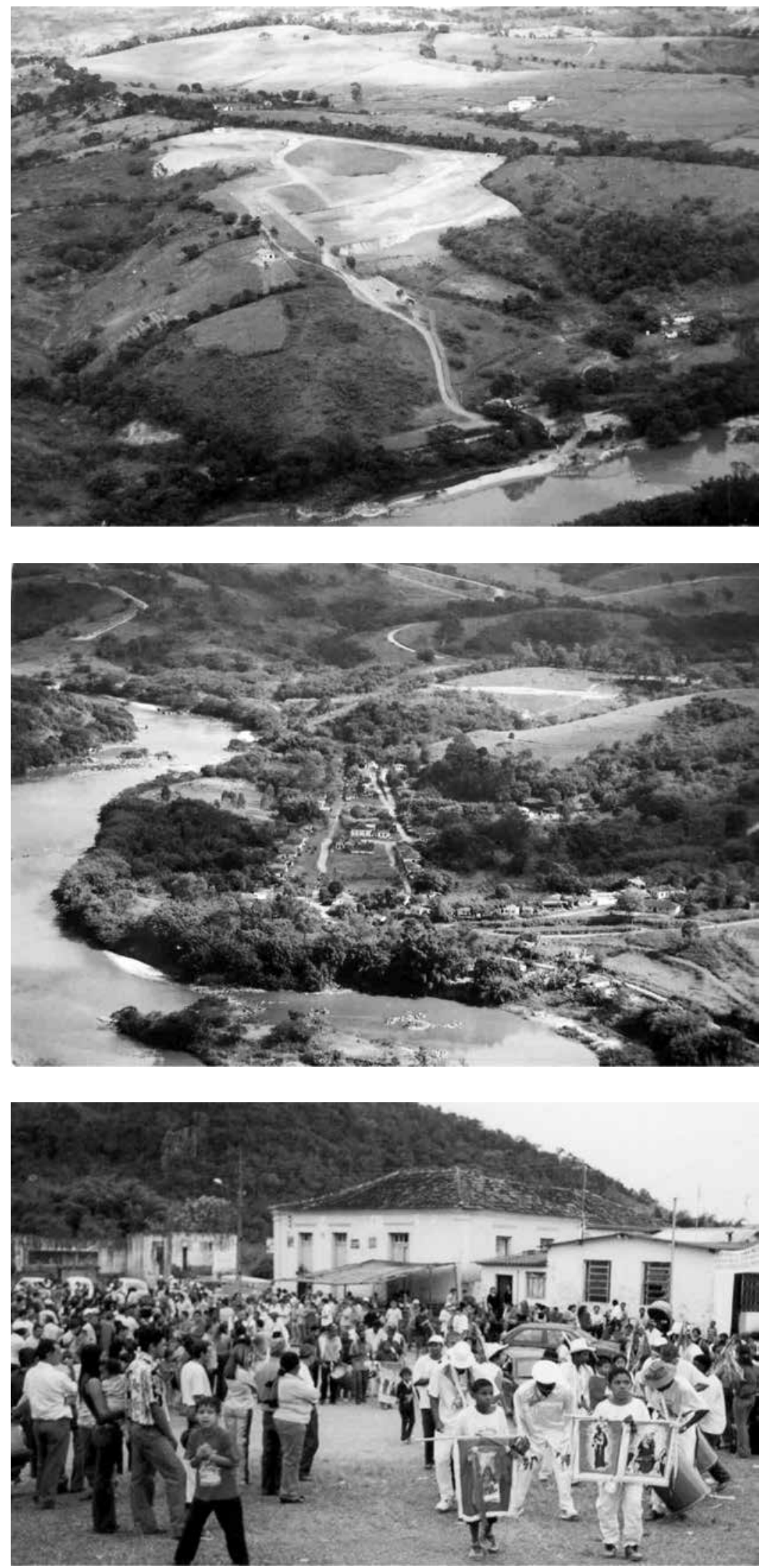

Figura 3: Remoção da cobertura vegetal para criação da infraestrutura básica da UHE-FUNIL

Fonte: Prefeitura de ljaci, MG, 2001
Figura 4: Região de Pedra Negra antes da formação do lago da UHE-Funil, MG

Foto: Wildes, 2001
Figura 5: Procissão de despedida em Pedra Negra, antes da desocupação para enchimento do lago da UHE-Funil, MG Fonte: Prefeitura de liaci, MG, 2000 
Paisagens históricas e arqueológicas também foram afetadas com a destruição das matas que recobriam as antigas minerações de ouro, implicando também a perda de informações científicas sobre o processo natural de recuperação de áreas degradadas.

Os impactos relacionados aos aspectos socioeconômicos e que afetaram sobremaneira tanto a paisagem natural quanto a antrópica foram o remanejamento compulsório da população residente, a perda de locais de recreação e lazer, a paralisação das atividades produtivas, a perda da infra-estrutura social localizada na área de inundação e a alteração das relações socioculturais existentes.

O diagnóstico do meio socioeconômico contido no RIMA relata, conclusivamente, porém, de forma questionável, que a economia regional não seria muito afetada pela UHE-FUNIL e que, assim, não seriam elevados os impactos de caráter definitivo. Mais significativos mostrariam-se com relação às áreas de lazer e à vida da população atingida, por suas permanentes ligações com as praias, a pesca e a paisagem natural formada pelo rio Grande e seus afluentes.

Os sítios arqueológicos existentes na região do eixo da barragem e localizados nos canteiros de obra e áreas de empréstimo foram inevitavelmente afetados, considerando-se, ainda, o fato de a abertura de estradas e outros movimentos de terra implicarem em danos ou destruição de sítios arqueológicos, com reflexos negativos sobre o meio, influenciando sobremaneira a paisagem local.

Destaca-se, também, a perda de elementos do patrimônio natural, localizados abaixo da cota de inundação, com conseqüente perda de espaço de lazer e mudança na estrutura paisagística, com destaque para as cachoeiras dos Uvás, Funil, Itapecerica, dos Pilões, além de praias e ilhas do rio das Mortes; também, todos os sítios arqueológicos localizados na área de inundação foram submersos.

\section{Interferências ambientais e características das novas paisagens a partir do início de operação da UHE-Funil}

A formação do reservatório da UHE-Funil provocou a perda de uma área de 40,457 $\mathrm{km}^{2}$, com reflexos nas paisagens natural, histórica e antrópica. Dentre as medidas mitigadoras, a proposta de salvamento do patrimônio natural constou da revegetação das áreas afetadas com gramíneas, além de recomendar que os remanescentes de vegetação nativa fossem preservados ao máximo (Figura 6).

Sobre as formações vegetais, os estudos e relatórios de impacto ambiental EIA-Rima previram que a formação do lago implicaria um aumento na pressão sobre os remanescentes de vegetação nativa localizados na Área de Influência - Al do empreendimento, em razão da redução da área ocupada por pastagens e cultivo agrícola. $\bigcirc$ impacto se daria com novos desmatamentos e intensificação do pastoreio nas áreas cobertas pelo campo limpo e campo cerrado, com reflexos negativos na nova paisagem.

Do ponto de vista socioeconômico, o Rima concluiu que o principal impacto previsto para a fase de operação da UHE-Funil foi o estabelecimento de uma nova paisagem local, cujo reflexo - prejuízo ou não para o meio ambiente - foi considerado de difícil 
qualificação. A alta magnitude desse impacto diz respeito à transformação do ambiente lótico (rio) em um ambiente de transição com características lênticas (lago) nos locais mais planos e, ainda, lóticas nos trechos mais encaixados (Figura 7).

A partir da fase de operação, previu-se que as áreas situadas no entorno do lago teriam uma forma distinta de ocupação do solo, referindo-se aos prováveis projetos de turismo, lazer e, mesmo, abertura de novas estradas. Os estudos realizados consideraram que as atividades turísticas deveriam ser incentivadas, inclusive como forma de integrar o empreendimento à região.

A formação do reservatório da UHE-Funil provocou uma desarticulação na organização do espaço regional, a partir do alagamento de parte da infra-estrutura social que ali existia. Assim, o projeto de recomposição da infra-estrutura social afetada teve como objetivo permitir a continuidade do processo de desenvolvimento da região e a inserção do empreendimento, para que as pessoas ali residentes pudessem continuar usufruindo os serviços oferecidos. Já o projeto de reativação econômica considerou três atividades que iriam influenciar, de forma significativa, a nova paisagem formada:
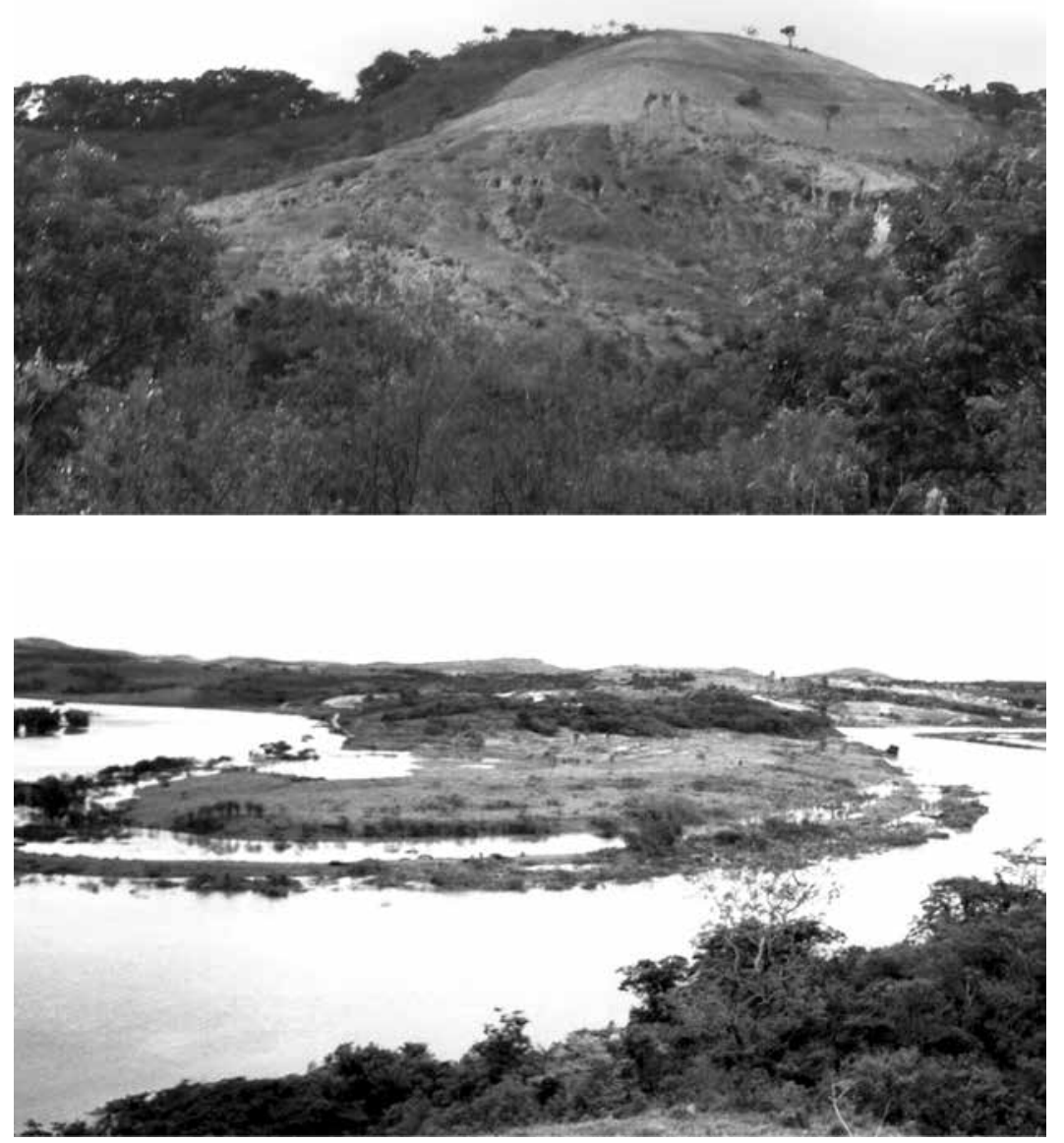

Figura 6: Início da revegetação de áreas degradadas no distrito do Rosário, município de ltumirirm, MG, em 2006

Fonte: Consórcio UHEFunil, 2006
Figura 7: Início da transformação da paisagem - ambiente lótico (rio) para lêntico (lago) da UHE-Funil Fonte: Prefeitura de ljaci, MG, 2002 
- Reativação econômica - com o objetivo de propiciar a reorganização das atividades econômicas da ADA, interrompidas com a formação do reservatório;

- recuperação de áreas degradadas - com a recomposição de solo e vegetação nas áreas do canteiro de obras, alojamentos, pedreiras e bota-fora;

- implantação da estação ecológica e de Áreas de Preservação Permanente - APP's.

Quanto à reativação econômica, alguns projetos têm sido implantados em determinadas áreas do entorno do reservatório, como na Comunidade do Funil, dotada de uma razoável estrutura esportiva e de pesca, além de bares e restaurantes. Pode-se destacar, também, a formação de uma associação de produtores rurais para a produção de maracujá na mesma região.

Fazendo parte do projeto de implantação da estação ecológica, não-efetivado até o presente momento (2008), e de legalização das áreas de preservação permanente APP's, o ElA-Rima menciona a formação de uma ilha com aproximadamente 138 ha, próxima à área de confluência dos rios das Mortes e Capivari, caracterizada como uma das mais importantes novas paisagens formadas pelo lago. Foi proposta, na fase de estudos, sua transformação em área de preservação permanente - APP, atendendo à legislação ambiental e, também, por possuir um remanescente de mata, além de forma-

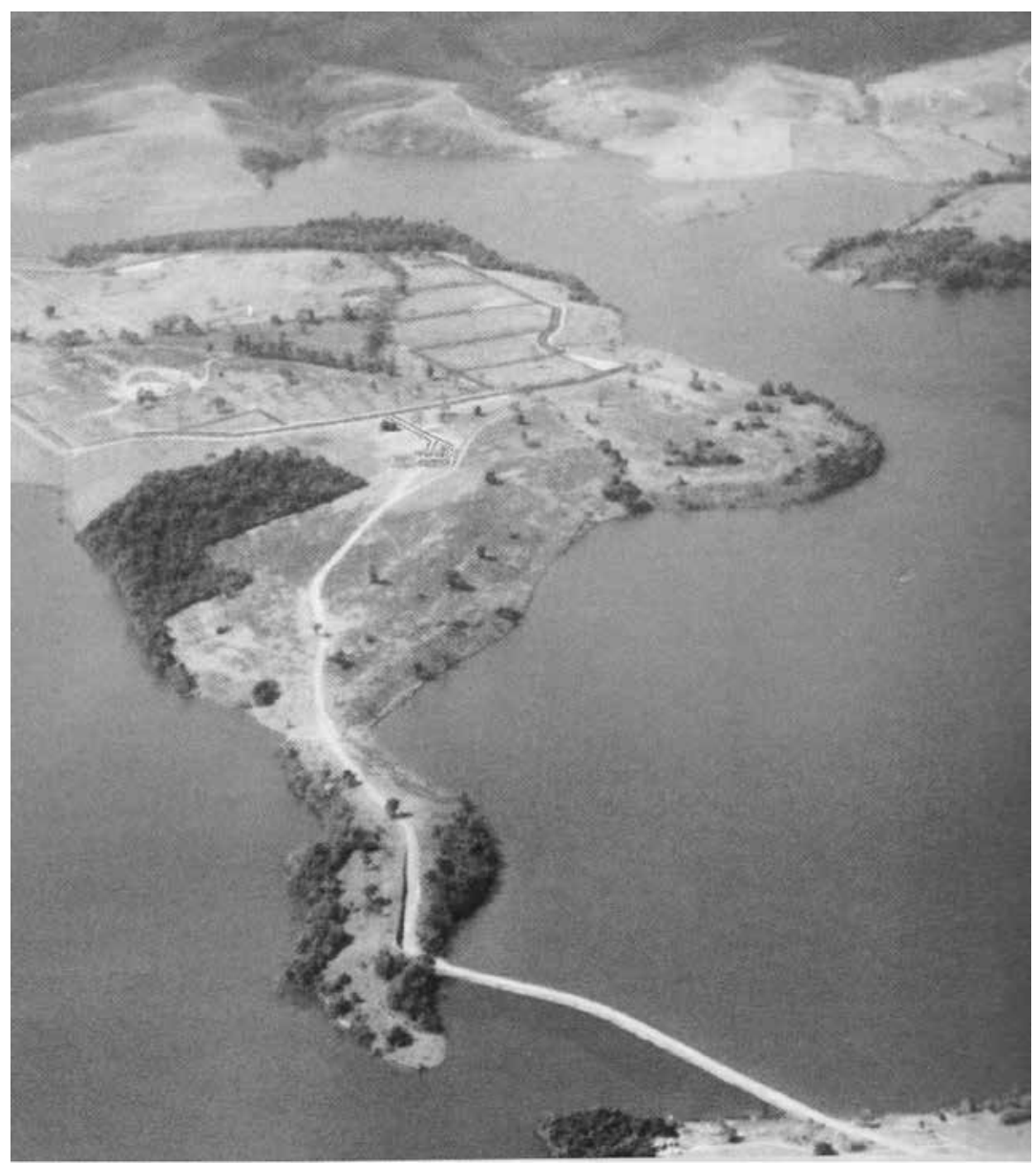

Figura 8: Iha formada pelo lago da UHE-Funil e transformada em condomínio Fonte: MG-4, material publicitário, 2004 
ções abertas de campo antrópico e cultivo agrícola, importantes para o restabelecimento de populações da flora e da fauna. Essa proposta não foi efetivada e o Plano Diretor do Município de liaci, contrariando a lei, enquadrou a ilha como "área de expansão urbana", transformado-a em um condomínio de segundas residências (Figura 8).

\section{CONCLUSÕES}

Nas fases de estimativa preliminar e inventário para o AHE-Funil, os estudos se basearam em sondagens geológicas sobre fatores que determinam, ou não, a construção de uma hidrelétrica. Não houve uma análise integral da paisagem que ponderasse outras possibilidades de uso de seus recursos naturais.

Ainda que a resolução Conama n. 001/86 determine que sejam contempladas todas as alternativas tecnológicas e de localização do projeto, confrontando-as com a hipótese da não-execução, o Relatório de Impacto Ambiental, Rima, do AHE-Funil não apresentou uma diagnose de potencialidade para a área/paisagem local.

A análise do EIA-Rima e de toda a documentação correlata permitiu estabelecer uma análise temporal da paisagem, com três estágios de transformação: dos primórdios da ocupação antrópica até a época do EIA-Rima; modificações quando da construção e enchimento da barragem e o surgimento de novas paisagens após a construção.

A UHE-Funil se insere na unidade geomorfológica "Superfície Cristalina do Alto Rio Grande", com tipos litológicos diversos, refletindo em diferentes tipos de solo e em uma ampla superfície de relevo ondulado; a estrutura da vegetação na área de influência do empreendimento tem o cerrado (lato sensu) como formação principal.

A área de influência do AHE-Funil foi cenário de ocupação indígena no passado, a que se seguiu o ciclo do ouro com a chegada dos bandeirantes, que deu lugar ao ciclo agropastoril, com a introdução da lavoura cafeeira e da construção da Estrada de Ferro Oeste de Minas e que, hoje, incorpora o processo industrial.

O ElA-Rima considerou que a alteração da paisagem com a implantação do reservatório, se, por um lado, acarretou perda de locais de lazer e de referências físico-culturais, por outro, significa a formação de um novo ambiente ecologicamente saudável, com oportunidades de lazer e turismo.

O EIA seguiu normas estabelecidas pela Resolução Conama n. 001/86, que estabelece diretrizes específicas para o estudo do meio físico, meio biótico e meio socioeconômico da área, em processo de desconstrução e fragmentação da paisagem, sem uma avaliação integral da mesma e, tampouco, sem uma projeção da nova paisagem que surgiria.

\section{Notas}

(1) Criptossistema: A parte oculta de um sistema, no caso, a paisagem e fenossistema como sendo a expressão, o fenótipo do criptossistema. 


\section{Bibliografia}

ALIER, J. M. Introducción a la economia ecológica. Cuadernos de Medio Ambiente, Espanha, 1999.

APROVEITAMENTO HIDRELÉTRICO DO FUNIL - AHE-FUNIL. Histórico. Disponível em: http://www.ahefunil.com. br/home/institucional/apresenta.htm. Acesso em: 14 mar. 2005.

BRASIL. CÂMARA DOS DEPUTADOS. Título VIII - Da Ordem Social, Cap. VI - do Meio Ambiente, Art. 225. Constituição da República Federativa do Brasil. Brasília: Coordenação de Publicação, 1999.

BRASIL. Instituto Brasileiro do Meio Ambiente e dos Recursos Naturais Renováveis. Brasília: Ministério do Meio Ambiente, 2000. Disponível em: <http://www.ibama.gov.br/>.

CENTRAIS ELÉTRICAS BRASILEIRAS - ELETROBRÁS. Manual de estudos de efeitos ambientais dos sistemas elétricos. Rio de Janeiro: Eletrobrás, 1986.

FEARNSIDE, P. M. Balbina: Lições trágicas na Amazônia. Ciência Hoje, Manaus, v. 11, n. 64, p. 34-40, 1990.

FUNDAÇAO ESTADUAL DO MEIO AMBIENTE - FEAM. Legislação ambiental. 2005, GER001. Disponível em: $<$ http://www.meioambiente.mg.gov.br/>.

GAVILANES, M. L.; BRANDÃO, M. Informações preliminares acerca da cobertura vegetal do município de Lavras, MG. Belo Horizonte: Daphane, v. 1, n. 2, p. 44-50, 1991.

INTERTECHNE CONSULTORES ASSOCIADOS S/C LEME ENGENHARIA LTDA. Estudo de Impacto Ambiental EIA. Belo Horizonte: FEAM, v. I a IV, 1992.

1992. . Estudo de Impacto Ambiental - ElA - Complementação de informações. Belo Horizonte: Intertechne, . Relatório de Impacto Ambiental - RIMA. Belo Horizonte: Intertechne, 1992.

PEREIRA et al. Análise e avaliação de impactos ambientais. Lavras-MG: Ufla/Faepe, 2001.

REIS, L. B. dos; FADIGAS, E. A. A.; CARVALHO, C. E. Energia, recursos naturais e a prática do desenvolvimento sustentável. Barueri: Manole, 2005.

RIZZINI, C. T. Preliminares acerca das formações vegetais e de reflorestamento no Brasil Central. Rio de Janeiro: SAI, 1962.

ROSA, L. P.; Sigaud, L.; La Rovere, E. L. O caso das grandes barragens: Impactos sociais da hidrelétrica de Tucuruí. Estado, energia elétrica e meio ambiente. Rio de Janeiro: La Rovere Universidade Federal do Rio de Janeiro, 1995. (COPPE/UFRJ), p. 5-7. 1995. Disponível em: <http://www.philip.inpa.gov.br/publ_livres/mss\%20and\%20in\%20 press/tuc-soc-por-inpa.pdf ->. 